\title{
Parameters of Postocclusive Reactive Hyperemia Measured by Near Infrared Spectroscopy in Patients with Peripheral Vascular Disease and in Healthy Volunteers
}

\author{
Rudi KragelJ, ${ }^{1}$ Tomaž Jarm, ${ }^{1}$ TAtjana ErJavec, ${ }^{2}$ MarJeta PrešErn-ŠTrukelu, ${ }^{2}$ \\ and DAMIJAN MIKLAVČIC ${ }^{1}$ \\ ${ }^{1}$ University of Ljubljana, Faculty of Electrical Engineering, Tržaška 25 and ${ }^{2}$ Institute of the Republic of Slovenia \\ for Rehabilitation, Linhartova 51, SI-1000 Ljubljana, Slovenia
}

(Received 27 April 2000; accepted 29 January 2001)

\begin{abstract}
The main purpose of our study was to determine the parameters of the postocclusive reactive hyperemia test that could help and provide the clinician with information about the tissue oxygenation, the severity of the disease, and the results of the applied therapies. Near infrared spectroscopy (NIRS) proved to be a valid noninvasive trend monitor useful for investigating the physiology of oxygen transport to tissue. Important advantages of NIRS over transcutaneous oximetry $\left(\mathrm{TcpO}_{2}\right)$ are: (a) a more dynamic nature of the NIRS signals which reflects more closely the actual response of the peripheral vasculature to the occlusive provocation; (b) larger sampling volume; and (c) the ability of assessing tissue oxygenation at deeper tissue levels. We demonstrated that the time parameters of reactive hyperemia, the rate of reactive hyperemia, and the maximal change during reactive hyperemia, all calculated from the oxyhemoglobin $\left(\mathrm{HbO}_{2}\right)$ signal of the NIRS, clearly distinguish between healthy volunteers and patients with vascular disorder. The time parameters of reactive hyperemia were significantly longer $(p<0.01)$, and the rate of reactive hyperemia $(p=0.01)$ as well as the maximal change during reactive hyperemia $(p=0.02)$ were significantly lower in patient group compared to healthy volunteers. These parameters were also in good correlation with the values of ankle brachial index $(\mathrm{ABI})$ and the resting values of oxygen partial pressure $\left(\mathrm{TcpO}_{2}\right)$. Values of the chosen parameters obtained from the $\mathrm{HbO}_{2}$ signal were further compared between groups of diabetic and nondiabetic patients with peripheral vascular disease. Although longer time parameters of reactive hyperemia and lower rates of hyperemic response were detected, the difference between both groups was not statistically significant. (C) 2001 Biomedical Engineering Society. [DOI: 10.1114/1.1359451]
\end{abstract}

Keywords-Noninvasive methods, Near infrared spectroscopy, Transcutaneous oximetry, Tissue oxygenation, Ischemia, Peripheral vascular disease.

\section{INTRODUCTION}

Atherosclerosis, the principal cause of diseases such as heart attack, stroke, and gangrene of the extremities, is

Address correspondence to Damijan Miklavčič, Faculty of Electrical Engineering, Tržaška 25, SI-1001, Slovenia. Electronic mail: damijan@svarun.fe.uni-lj.si responsible for $50 \%$ of all mortality in the USA, Europe, and Japan. ${ }^{30}$ Disorders of the peripheral vascular system are one of the most common symptoms of the developed atherosclerotic process. Early detection of the vascular abnormalities is therefore important to prevent the progress of the disease to its severe forms (critical limb ischemia, gangrene, and finally amputation of the extremity) or to predict coincidence of the atherosclerotic changes in vasculature of vital organs.

In patients with lower limb ischemia, not only the circulation through the larger blood vessels, but also the microcirculatory perfusion is disturbed. ${ }^{34}$ The microvascular disturbance, characterized by reduced blood flow in capillaries and impaired tissue oxygenation, plays a key role in tissue viability and in most cases leads to tissue necrosis or gangrene. ${ }^{18,34}$ The local microcirculation of the tissue at risk cannot be evaluated by perfusion and flow measurements on the level of macrocirculation. The number and diversity of the various techniques indicates that absolute assessment of microcirculation is not a simple problem and to date no "gold standard" exists. ${ }^{1,31}$ Laser doppler flowmetry gives relative values of blood perfusion in skin capillaries but the limitations of the technique (unknown origin of the signal) restrict its clinical usefulness. ${ }^{23,25,33}$ Transcutaneous oximetry $\left(\mathrm{TcpO}_{2}\right)$ is widely used by vascular surgeons and angiologists. $\mathrm{TcpO}_{2}$ values are used to indicate indirectly the skin perfusion, define amputation levels in some patients, and predict the healing of ulcers, ${ }^{1,34}$ although it is still not clear if the $\mathrm{TcpO}_{2}$ value reflects the underlying tissue oxygen partial pressure. ${ }^{31}$

Obstructions of the vascular system either on the macrocirculatory or the microcirculatory level reduce oxygen availability. Impaired oxygen transport, where oxygen supply does not meet the demand, can lead to functional and structural disturbances of organs and tissues. ${ }^{32}$ Conventional noninvasive methods measure variables, such as blood flow and partial pressure of oxygen. In order to 
TABLE 1. Clinical characteristics of the group of PVD patients and the group of healthy volunteers. Values are presented as means (minimal/maximal value). Results of the MannWhitney Rank Sum Test are presented as exact $p$ values. The statistically significant level of difference was considered to be at $p<0.05$. ( $n$, number of subjects; $M$, male; $F$, female, ${ }^{*}$, statistically significant difference.)

\begin{tabular}{|c|c|c|c|c|c|c|c|}
\hline & & $\begin{array}{l}\text { Age } \\
\text { (yr) }\end{array}$ & $\begin{array}{c}\mathrm{TcpO}_{2} \\
(\mathrm{mmHg})\end{array}$ & $\mathrm{ABI}$ & $\begin{array}{l}\text { Diabetic } \\
\text { patients } \\
(n)\end{array}$ & $\begin{array}{l}\text { Hypertension } \\
(n)\end{array}$ & $\begin{array}{c}\text { Smokers } \\
(n)\end{array}$ \\
\hline PVD patients & $\begin{array}{c}n=24 \\
(20 M / 4 F)\end{array}$ & $\begin{array}{c}63.7 \\
(47 / 77)\end{array}$ & $\begin{array}{c}37.6 \\
(23 / 48)\end{array}$ & $\begin{array}{c}0.59 \\
(0.35 / 1.05)\end{array}$ & 13 & 3 & 13 \\
\hline $\begin{array}{l}\text { Healthy } \\
\text { volunteers }\end{array}$ & $\begin{array}{c}n=18 \\
(11 M / 7 F)\end{array}$ & $\begin{array}{c}61.3 \\
(47 / 75) \\
p=0.34\end{array}$ & $\begin{array}{c}54.4^{*} \\
(43 / 67) \\
p<0.01\end{array}$ & $\begin{array}{c}1.16^{*} \\
(0.92 / 1.40) \\
p<0.01\end{array}$ & 0 & 0 & 3 \\
\hline
\end{tabular}

assess the balance between oxygen delivery from blood to tissue and oxygen demand, a technique that could measure the oxygen levels within the intact tissues, would be ideal. ${ }^{24}$

Near-infrared spectroscopy (NIRS) is a relatively new optical technique for noninvasive monitoring of tissue oxygenation and hemodynamics on different physiological levels..$^{2,4,15,17,36,38}$ It allows the simultaneous measurement of changes in intravascular (hemoglobin), intramuscular (myoglobin), and mitochondrial (cytochrome $\mathrm{aa}_{3}$ ) oxygenation in $2-6 \mathrm{~cm}^{3}$ of the limb tissue. ${ }^{13}$ First clinical applications of this technique have principally been focused on the cerebral circulation. ${ }^{12,17,38,39}$ More recent studies indicate the clinical relevance of NIRS measurement on muscle. The NIRS technique has been used to quantify human skeletal muscle oxygen consumption, 5,8 blood flow, ${ }^{9,11}$ and venous saturation. ${ }^{40}$ Trends in human skeletal muscle deoxygenation have been studied during cuff ischemia and excessive exercise. ${ }^{6,7,16}$ Many studies were made to investigate the peripheral vascular disease (PVD). Oxygen consumption $\left(\mathrm{VO}_{2}\right)$ was reported to be lower in PVD patients compared to healthy subjects. ${ }^{5}$ Several groups used a standardized treadmill exercise to investigate the calf oxygenation of patients with intermittent claudication. ${ }^{20,28}$ Oxygen resaturation, as an indication of oxygen debt and arterial inflow capacity, was highly correlated with ankle brachial index (ABI) at rest. Kooijman et al. ${ }^{21}$ found significant correlation between oxygen resaturation and $\mathrm{ABI}$ measured during and after the walking test. Muscle NIRS might also play a role in investigating the therapeutic efficacy of vasoactive substances on muscle oxygenation. ${ }^{26}$

One of the well-known tests in clinical practice for evaluating the functional aspects of the arterial blood flow in a limb is the reactive hyperemic response after a certain period of arterial occlusion. During the last decade several studies have been performed using the test of postocclusive reactive hyperemia (PORH) in patients with PVD, ${ }^{5,20,21,24,28}$ however the designs of these studies have varied from one study to another. It is difficult to get a specific conception regarding the validity of the technique for evaluating tissue oxygenation and blood perfusion in patients with PVD. Therefore there is an evident necessity to standardize the test of PORH.

The main purpose of the study was to determine the PORH parameters at different levels of arterial disease that could help and provide the clinician and/or researcher with important information about tissue oxygenation, the severity of the disease, and the results of the applied therapy and the wound healing potential of a limb with an open wound or one that may need amputation. In order to fulfill the task we: (1) examined the applicability of NIRS for quantification of PORH; (2) calculated the parameters of the PORH test in a group of healthy volunteers and a group of PVD patients; (3) proposed the most useful parameters that can be used to evaluate the state of the peripheral vasculature; (4) compared these results with the values of $\mathrm{ABI}$ index and with the results of $\mathrm{TcpO}_{2}$ measurement; and (5) compared values of the selected parameters on the groups of diabetic and nondiabetic PVD patients.

\section{MATERIALS AND METHODS}

\section{Subjects}

A group of 24 patients with PVD and a group of 18 healthy volunteers were included in the study, after giving informed consent. The study was approved by the Ethical Committee of the Ministry of Health of the Republic of Slovenia. The measurements were performed in the morning. All subjects were asked to refrain from caffeine, nicotine, alcohol, and not to perform any extensive physical activity prior to the test. All the experiments were performed at the ambient temperature of $21^{\circ} \mathrm{C}$.

Clinical characteristics of the group of PVD patients and the group of healthy volunteers are presented in Table 1. All PVD patients were classified as having Fontain stage II PVD. The control group consisted of 18 age-matched healthy volunteers. None of them had a history of cardiovascular disease and no signs of PVD. 




A

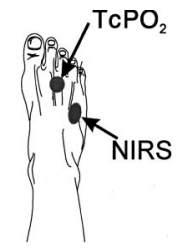

B

FIGURE 1. Schematical representation of the experimental setup (A) and location of the NIRS optodes and $\mathrm{TcpO}_{2}$ electrode (B).

The group of patients was divided into a subgroup of diabetic patients (13 patients mean age 65.4, range 47-77 yr, mean $\mathrm{TcpO}_{2}$ value at rest $37.8 \mathrm{~mm} \mathrm{Hg}$, range 23-48, and mean ABI 0.58, range 0.35-1.00), and a subgroup of patients without signs and history of diabetes mellitus (11 patients mean age 61.7, range 55-74 yr, $p=0.27$, mean $\mathrm{TcpO}_{2}$ value at rest $37.4 \mathrm{~mm} \mathrm{Hg}$, range 27-45, $p=0.76$, and mean ABI 0.61, range 0.37-1.05, $p=0.89)$.

\section{Near Infrared Spectroscopy}

NIRS is a noninvasive optical method for continuous measurement of tissue oxygenation and hemodynamics. In this study it was used for the assessment of tissue oxygenation in the distal parts of the lower limbs. The technique is based on two fundamental characteristics: (a) relative transparency of human tissue to light in the near infrared region (700-1000 $\mathrm{nm}$ ) and (b) the oxygenation-dependent absorption of oxyhemoglobin and oxymyoglobin $\left(\mathrm{HbO}_{2}, \mathrm{MbO}_{2}\right)$, deoxyhemoglobin and deoxymyoglobin $(\mathrm{Hb}, \mathrm{Mb})$. By measuring changes in light absorption at different wavelengths $(775,805,845$, and $905 \mathrm{~nm}$ ) changes in tissue oxygenation can be measured continuously. The relation between light absorption and concentration changes of chromophores is described by the modified Beer-Lambert law. ${ }^{10}$

A $\mathrm{NIRO}_{2}$-X2 instrument (Keele University, UK) was used for simultaneous monitoring of concentration changes of oxy- and deoxy hemoglobin $\left(\mathrm{HbO}_{2}\right.$ and $\left.\mathrm{Hb}\right)$. Summation of the changes in the concentration of $\mathrm{HbO}_{2}$ and $\mathrm{Hb}$ provides a measure of changes in the total tissue hemoglobin Hbtot, which reflects changes in the tissue blood volume. From the difference of $\mathrm{HbO}_{2}$ and $\mathrm{Hb}$ signals the oxygenation index (OI) can be derived. It gives an indication of the net hemoglobin oxygenation status. $^{32}$

\section{Experimental Protocol}

Figure 1 shows the experimental setup. All subjects were in a supine position during the measurement. The optical fibers (optodes) of the NIRS instrument were positioned on the dorsal and lateral surfaces of the foot

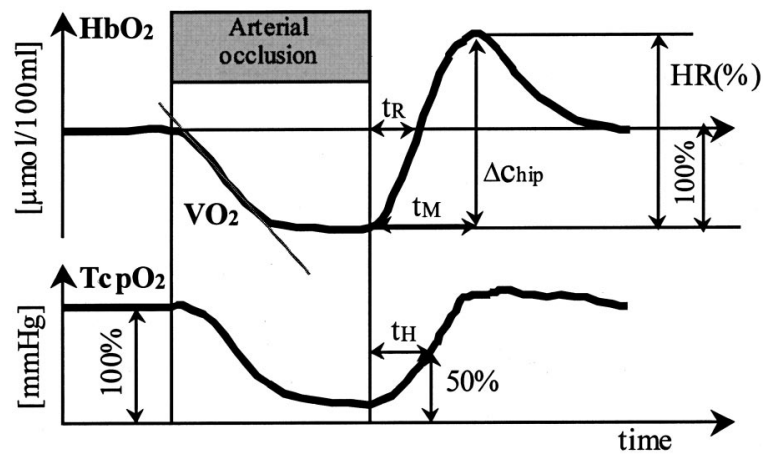

FIGURE 2. Parameters of postocclusive reactive hyperemia evaluated from NIRS and $\mathrm{TcpO}_{2}$ signals $\left[\left(\mathrm{HbO}_{2}\right)\right.$ oxyhemoglobin; $\left(\mathrm{TcpO}_{2}\right)$ transcutaneous oxygen partial pressure; $\left(\mathrm{VO}_{2}\right)$ oxygen consumption; $\left(t_{R}\right)$ time of recovery; $\left(t_{M}\right)$ time to peak value; $\left(\Delta c_{\text {hip }}\right)$ maximal change of the NIRS signal; (HR) maximal hyperemic response; $\left(t_{H}\right)$ half time of the response].

between the fourth and the fifth digit [Fig. 1(B)]. The measurement was performed in the transmission mode. The optodes were attached to the skin by a support that allowed both the distance and the angle between the optodes to be maintained constant during the test. Geometrical distance between the optodes was approximately $4 \mathrm{~cm}$ in all subjects. The differential pathlength factor value was 4.3. ${ }^{9}$ The sampling rate was $1 \mathrm{~Hz}$. The data collected by NIRS were transferred online to a personal computer for storage and subsequent analysis. Data collection program NIRDCU 4.81 (Keele University, UK) was used for instrument control and data acquisition. A transcutaneous oxygen partial pressure meter (TCM2, Radiometer, Denmark) was used for oxygen partial pressure $\left(\mathrm{TcpO}_{2}\right)$ monitoring. The electrode was positioned on the upper surface of the same foot between the second and the third digits. The measurements were performed at an electrode temperature of $43^{\circ} \mathrm{C}$.

A 10 min rest period was allowed after the placement of all necessary equipment. Arterial occlusion was achieved by inflating a thigh cuff (CC17, Hokanson) to a pressure of $30 \mathrm{~mm} \mathrm{Hg}$ above the value of the individual systolic pressure of each subject. The cuff was placed above the knee on the thigh and inflated in less than 1 min to the pressure needed for the arterial occlusion. A standard cuff inflator (TD312, Hokanson) was used for this purpose. The cuff remained inflated for $5 \mathrm{~min}$ and then rapidly released.

\section{Parameter Evaluation}

Different parameters obtained by the two noninvasive methods were studied (Fig. 2):

(i) VO2, oxygen consumption, calculated from the 

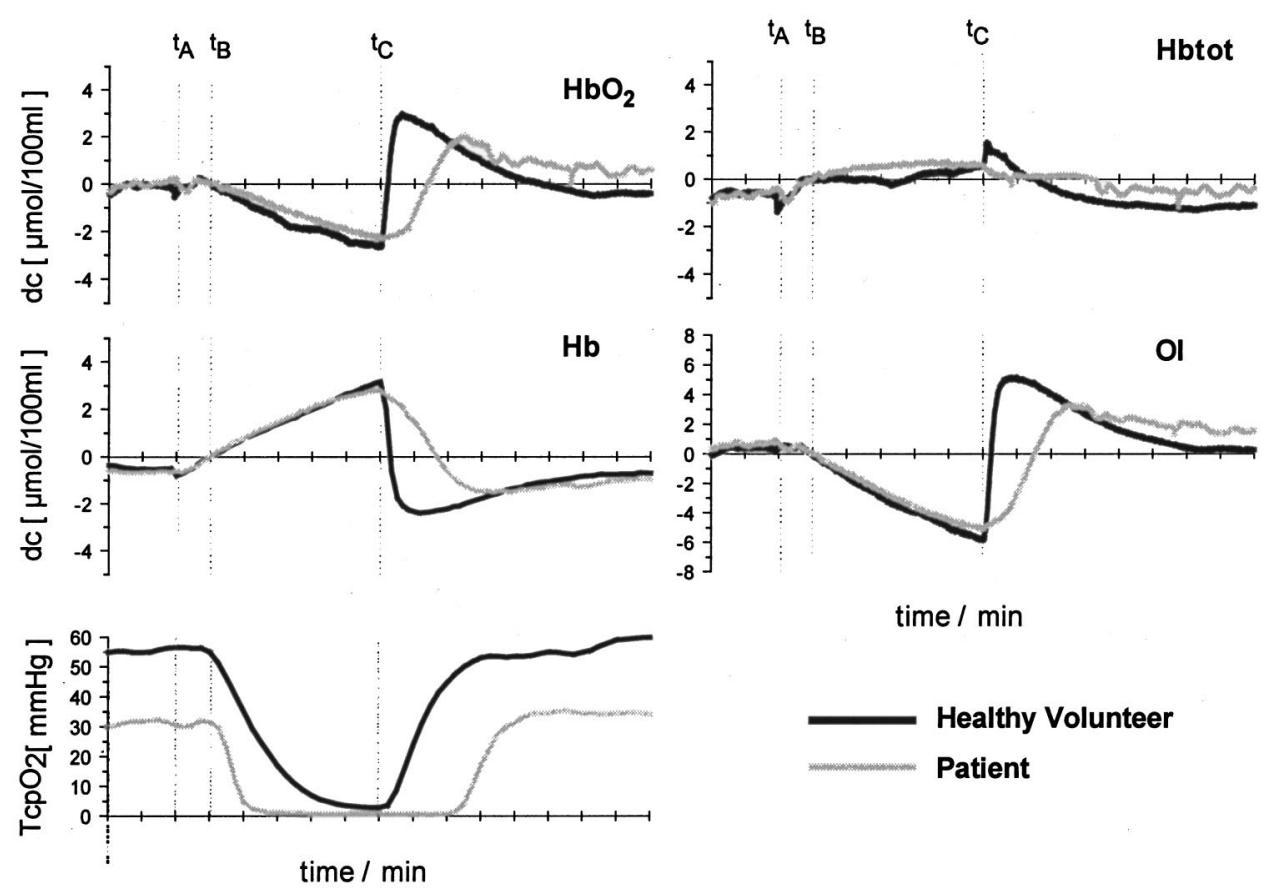

time / $\min$

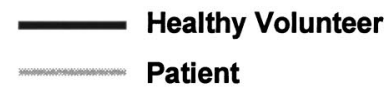

FIGURE 3. NIRS and $\mathrm{TcpO}_{2}$ responses from the foot of representative subjects from the group of patients with peripheral vascular disease and the group of healthy volunteers during $5 \mathrm{~min}$ arterial occlusion and subsequent recovery. $\left[\left(t_{A}\right)\right.$ time point of cuff inflation; $\left(t_{B}\right)$ time point of the start of arterial occlusion; $\left(t_{C}\right)$ time point of the end of arterial occlusion; $\left(\mathrm{HbO}_{2}\right)$ oxyhemoglobin; (Hb) deoxyhemoglobin; (Hbtot) total hemoglobin; (OI) oxygenation index].

gradient of the $\mathrm{HbO}_{2}$ signal during arterial occlusion and converted to $\mathrm{ml}^{-1} \mathrm{~min}^{-1}$ as described elsewhere, ${ }^{5,21}$

(ii) $t_{R}$, time of recovery (s), the time interval after release of the cuff until the initial values of $\mathrm{HbO}_{2}$, $\mathrm{Hb}$, and $\mathrm{OI}$ signals are reached;

(iii) $t_{M}$, time to peak value (s), the time interval after release of the cuff until 95\% of the signals peak values are reached;

(iv) $\mathrm{HR}$, maximal hyperemic response (\%), maximal change of the signal after the release of the cuff, expressed as the percentage of the signal change during arterial occlusion;

(v) $\Delta c_{\text {hip }}$, maximal change of the NIRS signal during the phase of reactive hyperemia expressed in $\mu \mathrm{mol} 100 \mathrm{ml}^{-1}$;

(vi) $\mathrm{TcpO}_{2}$, oxygen partial pressure value $(\mathrm{mm} \mathrm{Hg})$ measured prior to arterial occlusion; and

(vii) $t_{H}$, half time of the response, the time interval after release of the cuff until $50 \%$ of the initial $\mathrm{TcpO}_{2}$ is reached.

\section{Statistical Analysis}

In each group of subjects mean values, standard errors, minimal, and maximal values of oxygenation parameters obtained from NIRS and $\mathrm{TcpO}_{2}$ signals were calculated. Statistical significance between groups was tested by the Mann-Whitney Rank Sum Test. Exact $p$ values are given. The statistically significant level of difference was considered to be at $p<0.05$.

Regression analysis and the Spearman Rank Order test were used to compare the NIRS and $\mathrm{TcpO}_{2}$ parameters with the ABI parameters.

\section{RESULTS}

Figure 3 shows typical examples of NIRS and $\mathrm{TcpO}_{2}$ measurements obtained from a representative healthy volunteer and from a representative patient with PVD. At the time point $t_{A}$, after a $10 \mathrm{~min}$ rest period, inflation of the cuff was started. In less than $60 \mathrm{~s}$ the pressure in the cuff reached the desired value needed for arterial occlusion (time point $t_{B}$ ). The cuff remained inflated for 5 min and then it was rapidly released (time point $t_{C}$ ).

The $\mathrm{HbO}_{2}$ signal decreased from the beginning of the arterial occlusion. This decrease was mirrored by the increase of the $\mathrm{Hb}$ signal. The Hbtot signal, which corresponds to the changes of blood volume, increased slightly during a period of arterial occlusion. The OI signal showed a trend similar to the $\mathrm{HbO}_{2}$ signal, however the changes were larger as they are calculated from the difference of the $\mathrm{HbO}_{2}$ and $\mathrm{Hb}$ changes. No significant difference could be seen among the signals of PVD patients and healthy volunteers. At the time point $t_{C}$ the 
TABLE 2. Mean values, standard errors of the mean, minimal, and maximal values of the PORH parameters for the group of healthy volunteers and PVD patients. Results of the Mann-Whitney Rank Sum Test are presented as exact $p$ values. The statistically significant level of difference was considered to be at $p<0.05$. ( $\bar{X}$, mean value; S.E., standard error; Min., minimal value; Max., maximal value; *, statistically significant difference.)

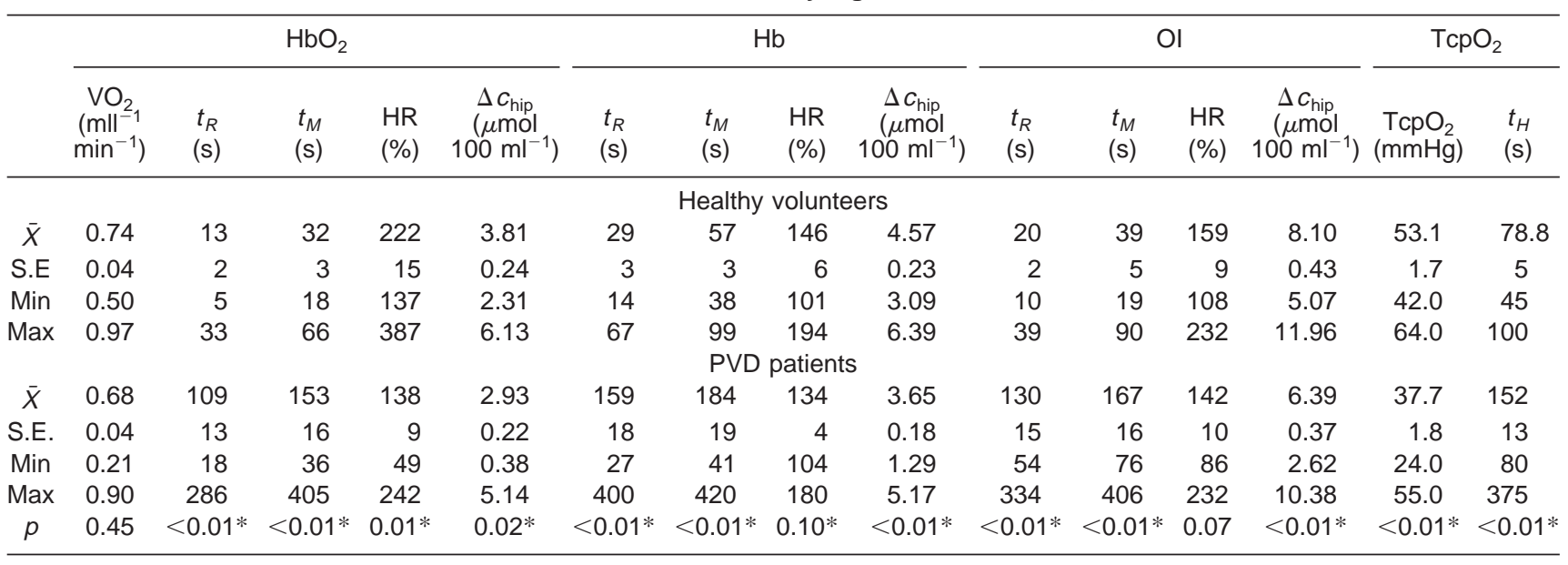

cuff was released and a hyperemic response was observed. The shape of the signals after the release of the arterial occlusion differs significantly between the group of PVD patients and the group of healthy volunteers. In healthy volunteers the increase of the $\mathrm{HbO}_{2}$ signal exceeded the decrease of the $\mathrm{Hb}$ signal immediately after the occlusion. This phenomena cannot be observed in the PVD patient group, where a decrease of Hbtot signal can be seen throughout the recovery period. In the healthy volunteer group a rapid reperfusion followed the release of the cuff. The reperfusion in the patient group is slower and in many subjects no hyperemic response was observed.

The value of $\mathrm{TcpO}_{2}$ decreased faster during the arterial occlusion in PVD patients compared to healthy volunteers. After the release of the arterial occlusion $\mathrm{TcpO}_{2}$ recovered slower in patients compared to healthy volunteers. No significant increase over the preocclusion value was observed in either patients or healthy volunteers. Comparison of the NIRS and $\mathrm{TcpO}_{2}$ signals showed that the $\mathrm{TcpO}_{2}$ method responded slower to the changes caused by the sudden release of the arterial occlusion (Fig. 3).

Values of the parameters of oxygen consumption $\left(\mathrm{VO}_{2}\right)$, recovery time parameters $\left(t_{R}\right.$ and $\left.t_{M}\right)$, percentages of the HR, and maximal absolute changes during reactive hyperemia $\left(\Delta c_{\text {hip }}\right)$ were calculated from the $\mathrm{HbO}_{2}, \mathrm{Hb}$, and $\mathrm{OI}$ signals. From the $\mathrm{TcpO}_{2}$ signals the absolute $\mathrm{TcpO}_{2}$ value at rest and half time of the response $\left(t_{H}\right)$ for each subject were determined. For both groups of subjects the mean value, standard error of the mean, the minimal, and the maximal value of all parameters are listed in Table 2. Individual values as well as the mean values and standard errors of the mean for the parameters obtained from $\mathrm{HbO}_{2}$ and $\mathrm{TcpO}_{2}$ in PVD pa- tients and healthy volunteers are presented in Fig. 4. Oxygen Consumption. The $\mathrm{VO}_{2}$ parameter, calculated from the decrease of the $\mathrm{HbO}_{2}$ signal, was lower in patients compared to healthy volunteers although the difference was not statistically significant $(p=0.45)$.

Recovery Time Parameters. Recovery times after arterial occlusion, expressed with parameters $t_{R}$ and $t_{M}$ for $\mathrm{HbO}_{2}, \mathrm{Hb}$, and $\mathrm{OI}$ signals, parameters were significantly longer in patients, and there was almost no overlaping between both groups $(p<0.01)$.

Reoxygenation Rates. The mean value of the parameter HR was lower in PVD patients compared to healthy volunteers. The difference between the group of PVD patients and the group of healthy volunteers was statistically significant for the parameter obtained from the $\mathrm{HbO}_{2}$ signal $(p=0.02)$, whereas the difference was not statistically significant for the parameters HR obtained from $\mathrm{Hb}(p=0.10)$ and $\mathrm{OI}(p=0.07)$ signals. The Maximal change of the $\mathrm{HbO}_{2}, \mathrm{Hb}$, and OI signal during the reactive hyperemia $\Delta c_{\text {hip }}$ was significantly lower in patients compared to healthy volunteers.

$\mathrm{TcpO}_{2}$. Absolute $\mathrm{TcpO}_{2}$ value and the half time of the response $t_{H}$ were significantly increased after the release of the arterial occlusion in PVD patients compared to healthy volunteers $(p<0.01)$.

The Spearman Rank Order Test was used to calculate correlation coefficients among the selected parameters and the values of the $\mathrm{ABI}$ index and $\mathrm{TcpO}_{2}$ measured at rest prior to the beginning of the PORH Test. Times of reactive hyperemia $\left(t_{R}\right.$ and $\left.t_{M}\right)$ obtained from signals $\mathrm{HbO}_{2}, \mathrm{Hb}$, and $\mathrm{OI}, \mathrm{HR}$ obtained from $\mathrm{HbO}_{2}$ signal, and half time of the $\mathrm{TcpO}_{2}\left(t_{H}\right)$ correlated well with the ABI index and $\mathrm{TcpO}_{2}$ value. Values of the Spearman correlation coefficient for these parameters varied from 0.55 to 0.73 . The other parameters did not correlate signifi- 


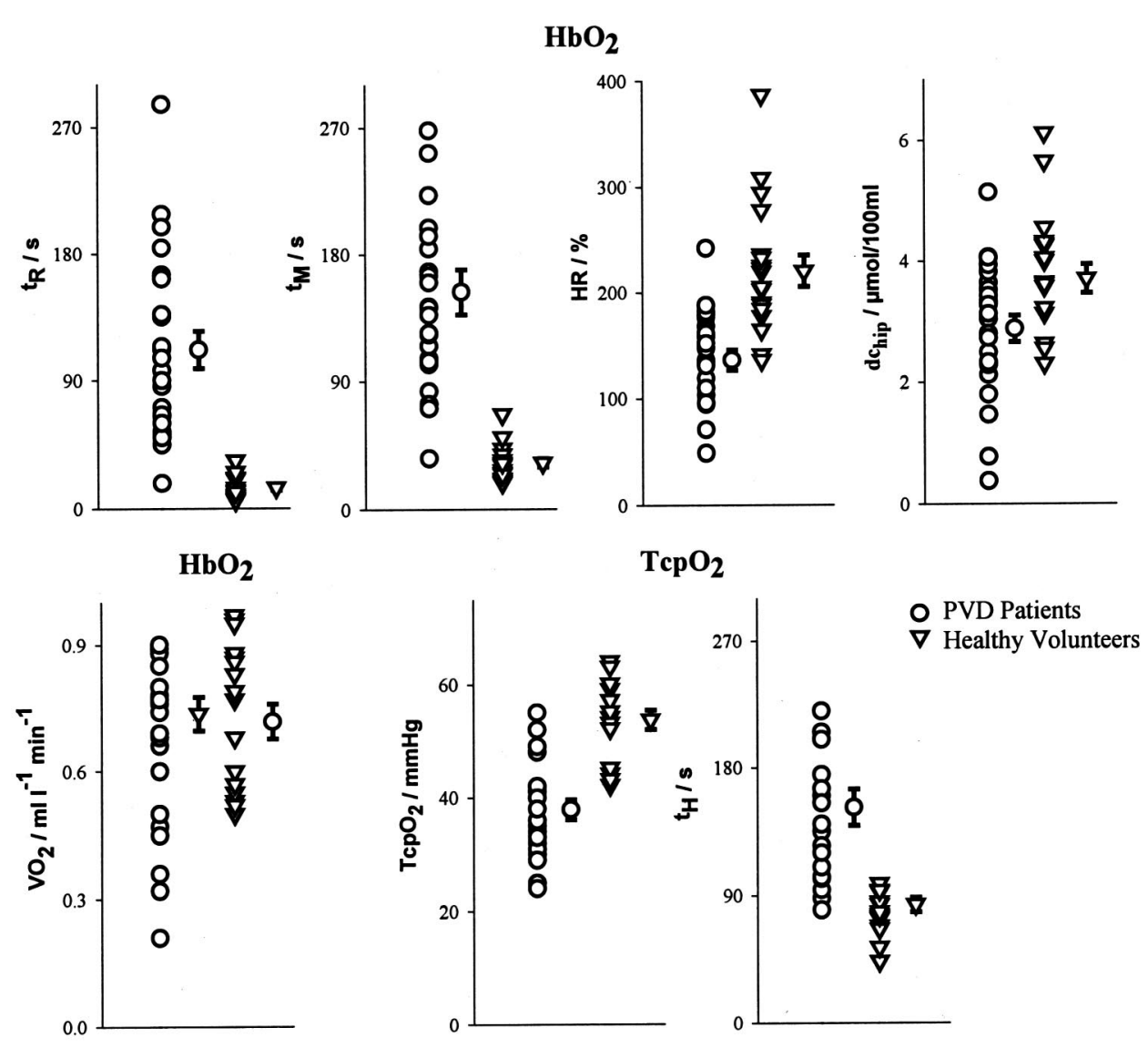

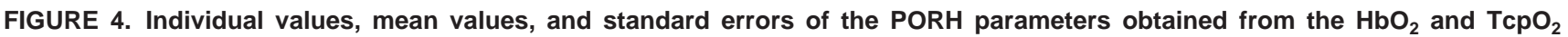
signals of PVD patients and healthy volunteers.

cantly with the $\mathrm{ABI}$ index and the $\mathrm{TcpO}_{2}$ value measured at rest prior to the beginning of the PORH Test. Correlation for the parameters obtained from the $\mathrm{HbO}_{2}$ signal and the $t_{H}$ parameter obtained from the $\mathrm{TcpO}_{2}$ is shown in Fig. 5.

PVD patients were further divided into two subgroups of diabetic and nondiabetic patients. A comparison of the $\mathrm{ABI}$ index, oxygenation parameters obtained from the $\mathrm{HbO}_{2}$ signals, and $\mathrm{TcpO}_{2}$ values between diabetic and nondiabetic patients was performed. Although there is a broad overlap between the two patients subgroups mean values showed delayed hyperemic response and lower reoxygenation rates in diabetic patients. The difference between selected parameters was however not statistically significant.

\section{DISCUSSION}

In this study we described the measurement and the determination of different parameters of the PORH test obtained by NIRS and $\mathrm{TcpO}_{2}$. NIRS proved to be a valid noninvasive trend monitor useful for investigating the physiology of oxygen transport to tissue. The potential importance of this new technique lies in the fact that it was found to be sensitive to changes in tissue oxygenation at the microcirculatory level. ${ }^{3,5,16}$ NIRS absorption changes are primarily attributed to the absorption of light in small blood vessels, such as capillary, arteriolar, and venular beds. ${ }^{27}$

The interpretation of the NIRS signals is based on the following assumptions. The NIRS technique measures the combined effect of changes in concentration of $\mathrm{Hb}$ and myoglobin (Mb). Myoglobin has almost identical absorption spectra to hemoglobin at NIRS wavelengths and the two chromophores cannot be separated by NIRS. It was found that in human muscles myoglobin contributed less than $25 \%$ to the NIRS signal ${ }^{3}$ and that deoxygenation of $\mathrm{Mb}$ occurs only after almost complete deoxygenation of $\mathrm{HbO}_{2}{ }^{35}$ The other assumption is that skin and subcutaneous fat contributed a negligible amount to the signal. It was shown that skin contributed less than $5 \%$ to the NIRS signal of the transilluminated human forearm. $^{29}$

In our study NIRS was compared with a technique currently used clinically for noninvasive monitoring of oxygenation. Simultaneously with the NIRS measure- 

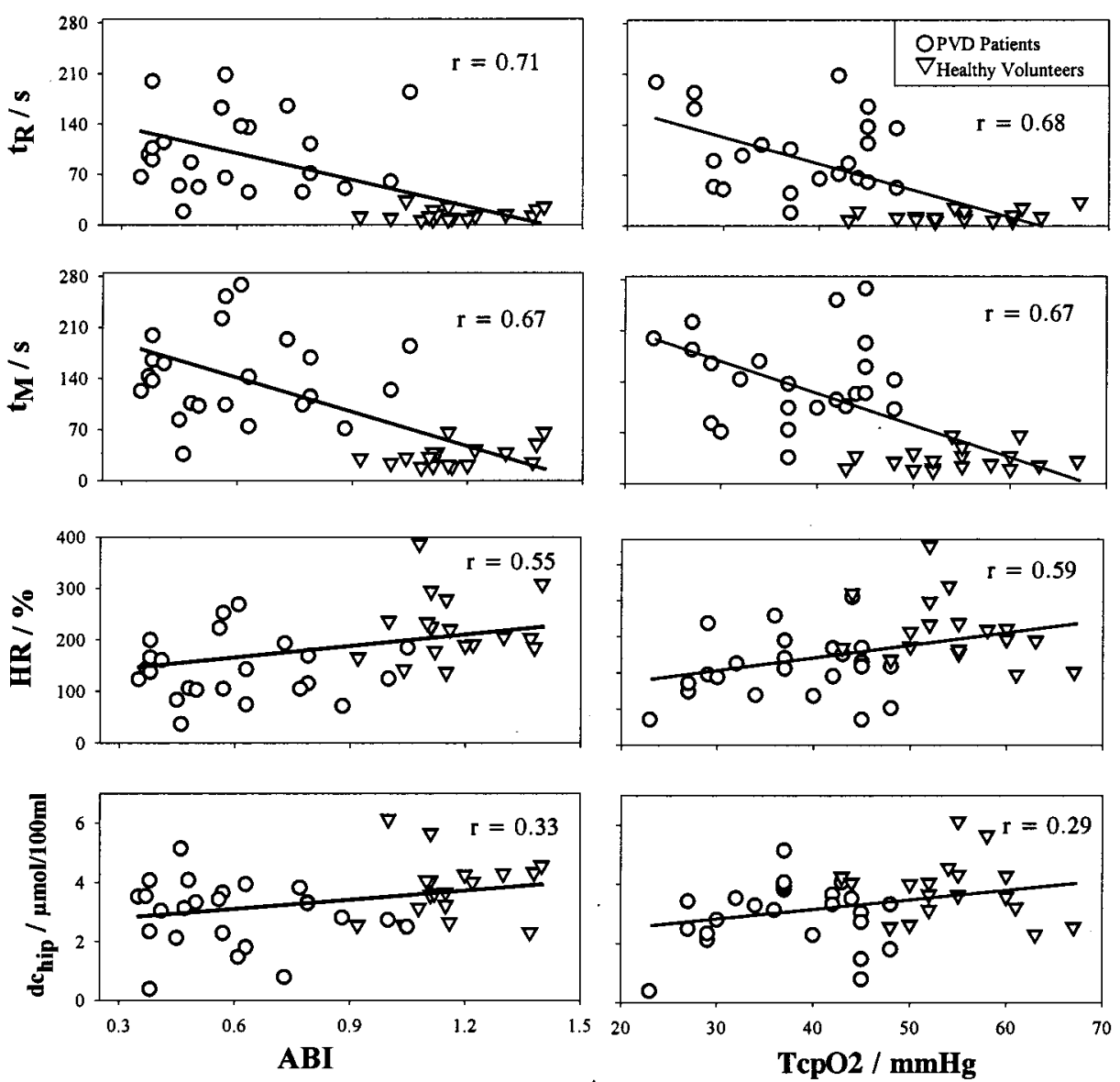

$\mathbf{A}$
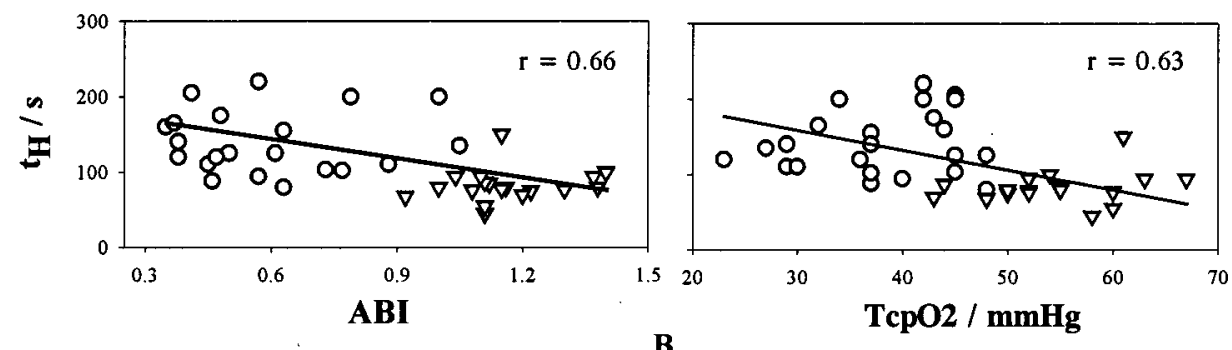

FIGURE 5. Correlation, represented as a linear regression, between the parameters of the $\mathrm{HbO}_{2}$ signal $\left(t_{R}, t_{M}, \mathrm{HR}\right.$ in $\left.\Delta c_{\text {hip }}\right)$ and values of the $A B I$ index and $\mathrm{TcpO}_{2}$, measured at rest prior to the beginning of the PORH Test (A). Correlation between the parameter $t_{H}$ of the $\mathrm{TcpO}_{2}$ signal and values of the $\mathrm{ABI}$ index and $\mathrm{TcpO}_{2}$, measured prior to the beginning of the PORH Test (B). Parameter $r$ represents the values of the Spearman correlation coefficient between the selected parameters.

ment the oxygen partial pressure was measured transcutaneously. An important advantage of NIRS over $\mathrm{TcpO}_{2}$ is that the more dynamic nature of the NIRS signals in comparison to the $\mathrm{TcpO}_{2}$ signal (Fig. 3) reflects more closely the actual response of the peripheral vasculature to the occlusive provocation. Due to larger measuring volume, with the possibility of detecting oxygenation changes in deeper tissue levels and better signal dynam- ics, the NIRS provides new valuable information that cannot be obtained by the $\mathrm{TcpO}_{2}$ alone.

One criticism of the study could be aimed at the relatively long time needed to inflate the cuff to the pressure of arterial occlusion. More than $30 \mathrm{~s}$ of inflation with the standard cuff inflator widely used in the clinical environment probably caused undesired venous occlusion prior to arterial occlusion. The resulting venous occlu- 
sion could probably lead to a wrong estimation of oxygen consumption ${ }^{5}$ and could in principle alter the tissue optical optical properties. ${ }^{9}$ Using a rapid cuff inflator, which will be capable of inflating the cuff within $1 \mathrm{~s}$, would probably lead to more precise observation.

$\mathrm{VO}_{2}$ at rest was not significantly different between the patients and the group of healthy volunteers $(p=0.45)$. Cheatle et al..$^{5}$ found the difference between both groups but reported a broad overlap of results. Kooijman et al. ${ }^{21}$ also reported no significant difference between both groups but found increased $\mathrm{VO}_{2}$ measured after walking exercise in PVD patients.

Recovery times $t_{R}$ and $t_{M}$ obtained from $\mathrm{HbO}_{2}, \mathrm{Hb}$, and OI index are significantly $(p<0.01)$ longer in PVD patients. Longer recovery times in PVD patients compared to healthy volunteers can be explained by slower resynthesis of phosphocreatine in this type of patient. ${ }^{19}$ Two other important reasons for the delayed response in PVD patients are probably rigidity and maximal vasodilatation of arterioles and capillaries. The mean time taken to reach $95 \%$ of the maximal $\mathrm{HbO}_{2}$ levels $(153 \mathrm{~s}$, range 36-405 s) was longer than recovery times reported by other studies where it was found to be $81 \mathrm{~s}^{21}$ or $40 \mathrm{~s}^{5}{ }^{5}$

Maximal hyperemic response expressed as the percentage of the signal change during arterial occlusion (HR) could be used as a measure of resaturation and could give some additional information about blood inflow and oxygen delivery to tissue after the release of the occlusion. The mean value of this parameter is lower in PVD patients compared to healthy volunteers, although the difference is statistically significant only for the parameter $\mathrm{HR}$ obtained from the $\mathrm{HbO}_{2}$ signal. Maximal changes of the $\mathrm{HbO}_{2}, \mathrm{Hb}$, and OI signals, expressed with the parameter $\Delta c_{\text {hip }}$, were significantly lower in patients. Significance of the parameter $\Delta c_{\text {hip }}$ is still not clear because of the principal limitation of NIRS that it cannot provide quantitative data but only reflects relative changes in oxygen transport to tissues.

A comparison of the PORH parameters revealed that the time parameters of reactive hyperemia most clearly distinguish between the group of PVD patients and the group of healthy volunteers. Furthermore the results showed that parameters $t_{R}, t_{M}, \mathrm{HR}$, and $\Delta c_{\text {hip }}$ obtained from the $\mathrm{HbO}_{2}$ signal are significantly different in PVD patients compared to healthy volunteers. From the results of the Spearman Rank Order Correlation Test it can be concluded that times of reactive hyperemia $\left(t_{R}\right.$ and $\left.t_{M}\right)$ obtained from $\mathrm{HbO}_{2}, \mathrm{Hb}$, and OI signals showed the best correlation with the values of the $\mathrm{ABI}$ index and $\mathrm{TcpO}_{2}$. The values of the correlation coefficients did not differ from those obtained by correlation of $\mathrm{TcpO}_{2}$ parameters and the ABI index. Although we presented the parameters calculated from different NIRS signals, the parameters obtained from the $\mathrm{HbO}_{2}$ signal are of the greatest importance. Results of our previous study showed that these parameters were suitably reproducible with the coefficient of variability varying from $5 \%$ to $35 \%$. $^{22}$ These results are also supported by the results of other groups. ${ }^{20,21,28}$

Diabetic patients, mainly because of their high levels of circulating cholesterol and other lipids, develop atherosclerosis and multiple microcirculatory lesions far more easily than do normal people. Late complications in diabetes mainly reflect disorders in microcirculation. ${ }^{14}$ Study of the parameters obtained from $\mathrm{HbO}_{2}$ signal in PVD patients with diabetes compared to PVD patients without signs and history of this disease showed delayed recovery times and lower reoxygenation rates in diabetic patients. Although the difference is not statistically significant, it supports previously reported results of other studies on diabetic patients. ${ }^{18,33}$ Joerneskog et al. ${ }^{18}$ studied skin capillary circulation in the foot of diabetic patients using laser Doppler flowmetry and also found lower and more delayed response in capillaries during the PORH Test. The reduced capillary circulation during reactive hyperemia can be explained as a consequence of several alterations in microcirculation, such as inability to dilate precapillary vessels, increased stiffness and thickness of capillary walls, endothelial cellular disfunction, etc. All these structural and functional changes in microcirculation of diabetic patients are more pronounced in the leg, most likely due to the higher hydrostatic pressure in this part of the body. ${ }^{37}$

From the results of this study it can be concluded that NIRS can be used to obtain valuable new information about the condition of peripheral vasculature, confirmation of disease diagnosis, assessment of the effects of disease on circulatory functions, and evaluation of the efficacy of vasoactive substances and therapies on the peripheral circulation. The main limitation of the technique in our case remains the incapability of measuring the absolute concentrations of the chromophores. The accuracy of quantitative data produced by NIRS is limited by inaccuracies in the estimation of optical path length for light transmitted through tissue. Until real time pathlength measurements are incorporated into the NIRS system, relative changes in chromophore concentration will form the basis of most NIRS studies. ${ }^{40}$

\section{ACKNOWLEDGMENTS}

This research was supported by the Ministry of Science and Technology of the Republic of Slovenia. The measurements were performed at the Institute of the Republic of Slovenia for Rehabilitation. 


\section{REFERENCES}

${ }^{1}$ Belcaro, R. M. et al. Noninvasive investigations in vascular disease. Angiology 49:673-706, 1998.

${ }^{2}$ Brazy, J. E. Near-infrared spectroscopy. Clin. Perinatology 18:519-534, 1991.

${ }^{3}$ Chance, B., M. T. Dait, C. Zhang, T. Hamaoka, and F. Hagerman. Recovery from exercise induced desaturation in the quadriceps muscles of elite competitive rovers. Am. J. Physiol. 262:C766-C775, 1992.

${ }^{4}$ Chance, B., S. Nioka, J. Kent, K. McCully, M. Fountain, R. Greenfield, and G. Holtom. Time resolved spectroscopy of hemoglobin and myoglobin in resting and ischaemic muscle. Anal. Biochem. 174:698-707, 1988.

${ }^{5}$ Cheatle, T. L., L. A. Potter, M. Cope, D. Delpy, P. D. Coleridge Smith, and J. H. Scurr. Near-infrared spectroscopy in peripheral vascular disease. Br. J. Surg. 708:405-408, 1991.

${ }^{6}$ Colier, W. N. J. M., I. B. A. E. Meeuwsen, H. Degens, and B. Oeseburg. Determination of oxygen consumption in muscle during exercise using infrared spectroscopy. Acta Anasthesiol. Scand. 39S107:151-155, 1995.

${ }^{7}$ De Blasi, R. A., M. Cope, and M. Ferrari. Oxygen consumption of human skeletal muscle by near infrared spectroscopy during tourniquet-induced ischemia in maximal voluntary contraction. Adv. Exp. Med. Biol. 317:771-777, 1992.

${ }^{8}$ De Blasi, R. A., M. Cope, C. Elwell, F. Safoue, and M. Ferrari. Noninvasive measurement of human forearm oxygen consumption by near infrared spectroscopy. Eur. J. Appl. Phys. 67:20-25, 1993.

${ }^{9}$ De Blasi, A. R., M. Ferrari, A. Natali, G. Conti, A. Mega, and A. Gasparetto. Noninvasive measurement of forearm blood flow and oxygen consumption by near infrared spectroscopy. J. Appl. Phys. 763:1388-1393, 1994.

${ }^{10}$ Delpy, D. T., M. Cope, P. Van Der Zee, S. R. Arridge, S. Wray, and J. S. Wyatt. Estimation of optical pathlength through tissue by direct time of flight measurement. Phys. Med. Biol. 33:1433-1442, 1988.

${ }^{11}$ Edwards, A. D., C. Richardson, P. Van Der Zee, C. Elwell, J. S. Wyatt, M. Cope, D. T. Delpy, and E. O. R. Reynolds. Measurement of hemoglobin flow and blood flow by near infrared spectroscopy. J. Appl. Phys. 754:1884-1889, 1993.

${ }^{12}$ Ferrari, M., C. De Marchis, I. Giannini, A. Nicola, R. Agostino, S. Nodari, and G. Bucci. Cerebral blood volume and hemoglobin oxygen saturation monitoring in neonatal brain by near infrared spectroscopy. Adv. Exp. Med. Biol. 200:203-213, 1986b.

${ }^{13}$ Ferrari, M., T. Binzoni, and V. Quaresima. Oxidative metabolism in muscle. Philos. Trans. R. Soc. London, Ser. B 352:677-683, 1997.

${ }^{14}$ Guyton, A. C., and J. E. Hall. Textbook of Medical Physiology 9th ed. Philadelphia, PA: Saunders, 1996.

${ }^{15}$ Hamaoka, T., H. Iwane, T. Shimomitsu, T. Katsumura, N. Murase, S. Nishio, T. Osada, Y. Kurosawa, and B. Chance. Noninvasive measures of oxidative metabolism on working human muscles by near-infrared spectroscopy. J. Appl. Physiol. 81:1410-1417, 1996.

${ }^{16}$ Hampson, N. B., and C. A. Piantodosi. Near infrared monitoring of human skeletal muscle oxygenation during forearm ischemia. J. Appl. Phys. 64:2449-2457, 1988.

${ }^{17}$ Jöbsis, F. F. Noninvasive infrared monitoring of cerebral and myocardial oxygen sufficiency and circulatory parameters. Science 198:1264-1267, 1977.

${ }^{18}$ Joerneskog, G., K. Brismar, and B. Fagrell. Pronounced skin capillary ischemia in the feet of diabetic patients with bad metabolic control. Diabetologia 41:410-415, 1998

${ }^{19}$ Keller, U., R. Oberhaensli, and P. Huber. Phosphocreatine content and intracellular $\mathrm{pH}$ of calf muscle measured by phosphorus NMR spectroscopy in occlusive and arterial disease of the legs. Eur. J. Clin. Invest. 15:382-388, 1985.

${ }^{20}$ Komiyama, T., H. Shigematsu, H. Yasuhara, and T. Muto. An objective assessment of intermittent claudication by near infrared spectroscopy. Eur. J. Vasc. Surg. 8:294-296, 1994.

${ }^{21}$ Kooijman, M. H., M. T. E. Hopman, W. N. J. M. Colier, J. A. Van Der Vliet, and B. Oeseburg. Near infrared spectroscopy for noninvasive assessment of claudication. J. Surg. Res. 72:1-7, 1997.

${ }^{22}$ Kragelj, R., T. Jarm, and D. Miklavčič. Reproducibility of parameters of postocclusive reactive hyperemia measured by near infrared spectroscopy and transcutaneous oximetry. Ann. Biomed. Eng. 28:168-173, 2000.

${ }^{23}$ Kvernebo, K., C. E. Slasgvold, and E. Stranden. Laser Doppler flowmetry in evaluation of skin post ischemic reactive hyperemia. J. Cardiovasc. Surg. 30:70-75, 1989.

${ }^{24}$ Lee, B. Y., L. E. Ostrander, M. Karmaker, L. Frenkel, and B. Herz. Noninvasive quantification of muscle oxygen in subjects with and without claudication. J. Rehabil. Res. Dev. 34:44-51, 1997.

${ }^{25}$ Liebert, A., M. Leahy, and R. Maniewski. Multichannel laser doppler probe for blood perfusion measurements with depth discrimination. Med. Biol. Eng. Comput. 36:1-8, 1998.

${ }^{26}$ Mancini, D. M., B. Chance, and J. R. Wilson. Effects of dobutamine on skeletal muscle oxygenation in patients with heart failure assessed by near infrared spectroscopy. Heart Failure 6:174-178, 1990.

${ }^{27}$ Mancini, D. M., L. Bolinger, H. Lui, K. Kendrick, B. Chance, and J. R. Wilson. Validation of near infrared spectroscopy in humans. J. Appl. Physiol. 77:2740-2747, 1994.

${ }^{28}$ McCully, K. K., C. Halber, and J. D. Posner. Exercise induced changes in oxygen saturation in the calf muscles of elderly subjects with peripheral vascular disease. J. Gerontol. Biol. Sci. 49:B128-B134, 1994.

${ }^{29}$ Piantodosi, C. A., T. M. Hemstreet, and F. F. Joebsis. Near infrared spectrophotometric monitoring of oxygen distribution to intact brain and skeletal muscle tissues. Crit. Care. Med. 14:698-706, 1986.

${ }^{30}$ Russel, R. The pathogenesis of atherosclerosis: A perspective for the 1990s. Nature (London) 362:801-809, 1993.

${ }^{31}$ Swain, I. D., and L. J. Grant. Methods of measuring skin blood flow. Phys. Med. Biol. 34:151-175, 1989.

${ }^{32}$ Thorniley, M. S., S. Simpkin, E. Balogun, K. Khaw, C. Shurey, K. Burton, and C. J. Green. Measurement of tissue viability in transplantation. Philos. Trans. R. Soc. London, Ser. B 352:685-696, 1997.

${ }^{33}$ Tur, E., G. Yosipovich, and Y. Bar-On. Skin reactive hyperemia in diabetic patients. Diabetes Care 14:958-962, 1991.

${ }^{34}$ Ubbink, D. T., M. J. H. M. Jacobs, and D. W. Slaaf. Can transcutaneous oximetry detect nutritive perfusion disturbances in patients with lower limb ischemia. Microvasc. Res. 49:345-324, 1995.

${ }^{35}$ Wang, D. J., E. A. Noyszewski, and J. S. Leigh. In vivo MRS measurement of deoxyhemoglobin in human forearms. Magn. Reson. Med. 14:562, 1990

${ }^{36}$ Wickramasinghe, Y. A. B. D., K. S. Palmer, R. Houston, S. A. Spencer, P. Rolfe, M. S. Thorniley, B. Oeseburg, and W. Colier. Effects of fetal hemoglobin on the determination of neonatal cerebral oxygenation by near-infrared spectroscopy. Pediatr. Res. 34:15-17, 1993.

${ }^{37}$ Williamson, J. R., and C. Kilo. Basement membrane physiology and patophysiology. International Textbook of Diabetes Mellitus, edited by K. G. M. M. Alberti, R. A. DeFronzo, 
H. Keen, and P. Zimmet, 1992, Vol. 2, pp. 1245-1265.

${ }^{38}$ Wyatt, J. S., M. Cope, D. T. Delpy, S. Wray, and E. O. R. Reynolds. Quantification of cerebral oxygenation and haemodynamics in sick newborn infants by infrared spectrophotometry. Lancet 8515:1063-1066, 1986.

${ }^{39}$ Wyatt, J. S., M. Cope, D. T. Delpy, C. E. Richardson, A. D. Edwards, S. Wray, and E. O. R. Reynolds. Quantification of cerebral blood volume in newborn human infants by near infrared spectroscopy. J. Appl. Phys. 68:1086-1091, 1990.

${ }^{40}$ Yoxall, C. W., and A. M. Weindling. Measurement of venous oxyhaemoglobin saturation in the adult human forearm by near infrared spectroscopy with venous occlusion. Med. Biol. Eng. Comput. 35:331-336, 1997. 